\title{
Index to Volume 4
}

Aaronson, J. AND Sullivan, D. Rational ergodicity of geodesic flows, 165

ADler, R. L. AND Flatto, L. The backward continued fraction map and geodesic flow, 487

Alexander, J. C. AND YORKE, J. A. Fat baker's transformations, 1

Auslander, J., MCMahon, D. C., VAN Der Woude, J. C. S. P. AND WU, T.-S. Weak disjointness and the equicontinuous structure relation, 323

Bamon, R., Malta, I. P., Pacifico, M. J. and Takens, F. Rotation intervals of endomorphisms of the circle, 493

BEREND, D. Minimal sets on tori, 499

BEREND, D. AND BERGELSON, V. Ergodic and mixing sequences of transformations, 353

Bergelson, V. See Berend, D. AND Bergelson, V.

BerNHARDT, C. Simple permutations with order a power of two, 179

BOYLE, M. Shift equivalence and the Jordan form away from zero, 367

BROER, H. W. AND VEGTER, G. Subordinate Šil'nikov bifurcations near some singularities of vector fields having low codimension, 509

CORNElis, E. AND WojTKowski, M. A criterion for the positivity of the Liapunov characteristic, 527

DANI, S. G. On orbits of unipotent flows on homogeneous spaces, 25

Denker, M. AND Philipp, W. Approximation by Brownian motion for Gibbs measures and flows under a function, 54I

DeVaney, R. L. AND KRYCh, M. Dynamics of exp (z), 35

DUISTERMAAT, J. J. Non-integrability of the $1: 1: 2$ resonance, 553

ELlIOTT, G. A. AND ZsıDó, L. One-parameter automorphism groups of operator algebras allowing spectral projections, 187

FATHI, A. Skew products and minimal dynamical systems on separable Hilbert manifolds, 213

Fiebig, U. R. A return time invariant for finitary isomorphisms, 225

FieldsteEL, A. Stability of the weak Pinsker property for flows, 381

Flatto, L. See Adler, R. L. ANd Flatto, L.

FranKs, J. Flow equivalence of subshifts of finite type, 53

GHys, E. Flots d'Anosov sur les 3-variétés en cercles, 67

GlasNer, S. AND RUDOLPH, D. Uncountably many topologicl models for ergodic transformations, 233

GUTKIN, E. Billiards on almost integrable polyhedral surfaces, 569

HALL, G. R. A topological version of a theorem of Mather on twist maps, 585

Hurley, M. Combined structural and topological stability are equivalent to Axiom $A$ and the strong transversality condition, 81

DEL JunCo, A. AND RudolPH, D. J. Kakutani equivalence of ergodic $Z^{n}$ actions, 89

Kalikow, S. A. Twofold mixing implies threefold mixing for rank one transformations, 237

Kaplan, J. L., Mallet-Paret, J. AND Yorke, J. A. The Lyapunov dimension of a nowhere differentiable attracting torus, 261

Krych, M. See Devaney, R. L. AND KRYCh, M.

LIND, D. A. The entropies of topological Markov shifts and a related class of algebraic integers, 283 


\title{
Ergodic theory and dynamical systems
}

\author{
EDITORS
}

Michel Herman Anatole Katok Klaus Schmidt Peter Walters

\section{EDITORIAL BOARD}

C. C. Conley (University of Wisconsin)

A. Connes (IHES)

R. L. Dobrushin (USSR Acad. of Sciences)

D. B. A. Epstein (University of Warwick)

J. Feldman (University of California)

J. Franks (Northwestern University)

H. Furstenberg (Hebrew University)

K. Jacobs (University of Erlangen)

H. Kesten (Cornell University)

U. Krengel (University of Gottingen)

W. Krieger (University of Heidelberg)

G. A. Margulis (USSR Acad. of

Sciences)
J. N. Mather (Princeton University)

M. Misiurewicz (Warsaw University)

S. E. Newhouse (University of Nth Carolina)

D. S. Ornstein (Stanford University)

J. Palis (IMPA)

W. Parry (University of Warwick)

D. Ruelle (IHES)

Ya. G. Sinai (L. D. Landau Inst. for Theoretical Physics, Moscow)

S. Smale (University of California)

J. P. Thouvenot (University of Paris 6)

W. A. Veech (Rice University)

B. Weiss (Hebrew University)

R. Zimmer (University of Chicago)

VOLUME 4

1984

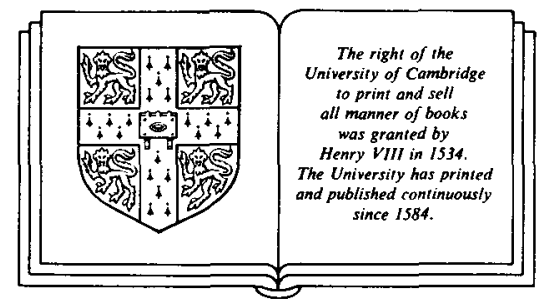

CAMBRIDGE UNIVERSITY PRESS

CAMBRIDGE

LONDON NEW YORK NEW ROCHELLE MELBOURNE SYDNEY 
McMahon, D. C. See Auslander, J., McMahon, D. C., van der Woude, J. C. S. P. And Wu, T.-S.

Mallet-Paret, J. See Kaplan, J. L., Mallet-Paret, J. and Yorke. J. A.

Malta, I. P. See Bamon, R., Malta, I. P., Pacifico, M. J. and Takens, F.

MATHER, J. N. Non-existence of invariant circles, 301

Misiurewicz, M. Twist sets for maps of the circle, 391

ORNSTEIN, D. AND WEISS, B. Any flow is an orbit factor of any flow, 105

Pacifico, M. J. See Bamon, R., Malta, I. P., Pacifico, M. J. and Takens, F.

PARRY, W. Bowen's equidistribution theory and the Dirichlet density theorem, 117

PEsin, YA. B. On the notion of the dimension with respect to a dynamical system, 405

Philipp, W. See Denker, M. ANd Philipp, W.

Pollicott, M. A complex Ruelle-Perron-Frobenius theorem and two counterexamples, 135

REES, M. Ergodic rational maps with dense critical point forward orbit, 311

RoBbIN, J. W. Unfoldings of discrete dynamical systems, 421

RoBINSON, C. Transitivity and invariant measures for the geometric model of the Lorenz equations, 605

Rudolph, D. J. See Glasner, S. AND RudolPh, D.

Rudolph, D. J. See DEl Junco, A. AND Rudolph, D. J.

Sullivan, D. See Aaronson, J. And Sullivan, D.

SzEwC, B. The Perron-Frobenius operator in spaces of smooth functions on an interval, 613

Takens, F. See Bamon, R., Malta, I. P., Pacifico, M. J. and Takens, F.

Vegter, G. See Broer, H. W. and Vegter, G.

Weiss, B. See ORNSTEIN, D. AND Weiss, B.

WILliaMs, R. F. Lorenz knots are prime, 147

WojtKowski, M. See Cornelis, E. AND WojtKowski, M.

van der Woude, J. C. S. P. See Auslander, J., McMahon, D. C., van der Woude, J. C. S. P. AND WU, T.-S.

Wu, T.-S. See Auslander, J., MCMahon, D. C., van der Woude, J. C. S. P. And Wu, T.-S.

Yorke, J. A. See Alexander, J. C. AND Yorke, J. A.

Yorke, J. A. See Kaplan, J. L., Mallet-Paret, J. And Yorke, J. A.

Zsidó, L. See Elliott, G. A. ANd Zsidó, L. 